\title{
Comparison on Cultural Connotation of Plant in Treasure Island and The Swordsman
}

\author{
XIONG Qian-li \\ Shanghai University of Sport, Shanghai, China
}

\begin{abstract}
In the development of human civilization, plant has been closely attached to human beings, and also been endowed with rich cultural imagery. However, ascribed to the differences between Chinese and English cultures, plant of the same kind exhibits similar, distinct or vacant characteristics. This paper adopts comparison method so as to compare and to analyze the differences and similarities of cultural connotation contained in plant emerging in Treasure Island (a representative of western adventure literature) and The Swordsman (a representative of Chinese martial arts literature) and roles plant plays in a certain chapter, or the whole story. The literature study presents a general knowledge of research theories in this field and cultural background. Moreover, the induction method integrates and summarizes the prior analyses and researches. Reasons underlying those cultural differences are also expounded, including legend and folklore, literature works and convention and custom. The conclusion is that analyzing the cultural connotation of plant is of significance for understanding the corresponding cultural differences as well as appreciating adventure and martial arts literature.
\end{abstract}

Keywords: plant, cultural connotation, martial arts literature, adventure literature

\section{Introduction}

Chinese martial arts literature has drawn much attention, thanks to the popularization of martial arts through some movies and stars. Among the few highly esteemed martial arts fiction writers, Jin Yong certainly stands out for his productivity and the impressive characters of his creation. The Swordsman is one the most popular fictions composed by Jin. In terms of genre, we fail to find equivalent in western literature for martial arts literary works. But we did find something very similar, i.e., adventure literature, which also tells wild heroic stories of characters with ambition and physical capability. Treasure Island serves as a good example in this aspect as well as in its popularity.

This paper tries to analyze the cultural connotation of plant in these two works, on the assumption that plant plays an important and interesting part in shedding light on the characters' personalities and accelerating the plot.

Treasure Island centered on a little boy named Jim who made stark use of meticulousness, courage and calm in the cause of treasure seeking. The clue of the whole story lies in the process relative to the emergence of treasure map, the pertinent people's reaction to every plot, etc. The story occurred in explicit setting narrated. Kui Hua Bao Dian in The Swordsman, not showing its mysterious origin or its terminal destiny, came into

XIONG Qian-li, Ph.D., Associate Professor, School of Sport Journalism and Foreign Languages, Shanghai, China. Email: edenxiong@163.com. 
being all of a sudden and disappeared with no avail.

Otherwise, The Swordsman is believed to have taken place in the late Ming Dynasty as written in the book, for the part of Jin Yong, the author, the story and humanity's greed and lust for fame and fortune can be perfectly appropriate if put in any dynasty or any place as stated its creator. Actually, Linghu Chong's personality and spirit go far beyond time and space, or gender, race or color.

Treasure Island attaches greater emphasis to proceeding of plot, The Swordsman to description of martial arts, mental activities, settings and individual's personality in spite of the plot.

To sum up, The Swordsman is more profound in ideology, more abundant in the number of heroes, more complex in plots and more multi-faceted in human nature than those of Treasure Island.

Despite the differences between the two books, there are also a plenty of similarities at the same time. To begin with, treasure and absolute master in martial art, to some extent, both of them mirror humanity's dark side, selfishness, greed and primitive lust for it by means, fair or foul. What's more, romantic complexity runs through The Swordsman which hits the pot of martial art huggers and romance fanatics while nothing about love affairs occurring in Treasure Island which is totally rare in the Western culture, especially in children's books. Last but not least, in light of destiny of treasure and Kui Hua Bao Dian, everyone obtains their share in the end, otherwise those who grasp Kui Hua Bao Dian trigger death and the secret arsenal went to extinction.

By analyzing the cultural connotation of plant appearing in Chinese martial arts and Western adventure literature, the paper will probe into the role plant plays in works of martial arts or adventure kind, such as artistic conception description, echo with theme, extending of theme, push of plot, etc. what's more, the relationship between language and culture will be further explored in the hope of drawing academia's attention to the important role which plant plays in works.

\section{Literature Review}

In this section, definitions of Chinese martial arts literature and Western adventure literature explain the main purpose and significance of the paper, status quo of plant research home and abroad, methods the paper need to elaborate, parse and solve problems, deeply and clearly.

Prevailing in the Western Europe in the Medieval Age, martial arts literature mirrored the ideal life of the Knight (Equestrian) class. The earliest knights on record obtained land and other rewards through fighting for big feudal aristocrats, hence evolution from small and medium-sized lords to small feudal aristocrats. They embraced feudalism in spirit and gradually formed a social class. Exposed to the oriental life style and culture, martial arts spirit took shape with emphasis on romantic love for noble women. An equestrian's supreme honor lies in the service of ladies and risk for love irrespective of Christian asceticism, in the pursuit of civilization and enjoying life. They brought the Oriental civilization to relatively backward Western European countries and France served as the most prosperous realm of martial arts literature with the genre: martial arts poetry, martial arts novel and counter-martial arts fiction.

The knight is protagonist, the incarnation of Super Hero, such as French volume the Song of Roland, which gives full expression to humility, honesty, honor, valor, sacrifice, justice, and compassion.

Adventure literature generally refers to adventure fiction, the kind of popular fiction which centers on various extraordinary adventure events. Protagonist, one or more, often experiences something unusual and undergoes unexpected frustrations which permeated with intense plots, sharp conflicts, thrilling scenes and weird and quirky stories. In a broad sense, adventure fiction has two major themes: description of interpersonal 
conflicts and of conflicts between an individual and social forces, description of conflicts between humanity and environment or nature. In a narrow sense, adventure fiction refers exclusively to the latter.

Adventure fiction can concentrate on some specific aspects, such as detective, thriller, history, buccaneer, romantic and action which boast The Lord of the Rings, The Call of the Wild, Spartacus, Gulliver's Travels, Sherlock Holmes Collection and the like.

Chinese scholar Guo Jing, in 2009, deeply analyzed and specifically categorized cultural connotation of plant and indicated the differences and similarities of the metaphorical significance on plant forms. The most typical case is that "wear the willow" in English means "Be mourning" or "Lament for the death of one's beloved”; while in Chinese culture, “willow” implies the sadness of departure. Wang Ying and Sun Liping’s essay published in 2006 has comprehensively discussed this point and concerned reasons why the different connotation of the same plant took place. In traditional Chinese culture, as Ding Shuifang and Ou Yamei in 2009 illustrated in detail, plant most widely-used was pine, bamboo and plum whose perseverance and unyieldingness was treated as the most appropriate objects.

Peter Newmark and Eugene A. Nida, the world-famous scholars, made a great contribution to enriching translation theories through describing connotation of language and culture as well as translation tactics all of which opened a totally new gate for translation and article understanding. Both of them attach tremendous importance to the original meaning of source text rather than stiffly literal translation or accurate correspondence of structure.

As for the deficiencies of current research, the important role which plant plays in literature has not been attached, home and abroad; nor cultural connotation in specific context. As far as I'm concerned, particulars of all implying whatever meaning can put icing on the cake, not be neglected.

From home and abroad, the image of plant often gives full expression to complex meanings and connotation, concerning love and hatred, passionate infatuation with each other and the atmosphere of euphemism for some specific reasons as well as female and male evolved from The Book of Songs.

There are a handful of relationships between Chinese and English plant in denotation and connotation, cultural connotation in particular. For instance, the same denotation with same or mostly same cultural connotation, the same denotation but different cultural connotation both of which are within the range of the same kind of plant. Different plants indicate the same cultural meaning and no exactly corresponding word implying the same connotation exists in both Oriented and Occidental cultures.

Thereupon, emphasis and attention should be attached to the connotations of plant appearing in literature in order to better comprehend the profound meaning and significance of what we are reading.

\section{Methodology and Theoretical Framework}

Comparison and contrast is the very first method to analyze the differences and similarities, between Chinese and Western, of plant in The Swordsman authored by Jing Yong and Treasure Island by Robert. Stevenson. Apple, for instance, in western culture refers to the source of misfortune and combats, such as Adam and Eve's dislodgement from Eden in Bible; while apple in traditional Chinese culture is merely a kind of fruit. Moreover, apple in Treasure Island was the crucial turning point for the whole story, and readers would guess that there is a turn in the course of events.

By literature, primary theories pertinent to what I would quote and texts as basis and setting of plant can be obtained. On the one hand, theories are those of Eugene A Nida's from language, culture, and contexts in 
translation and a series of essays on plant's cultural connotation both in China and the West; on the other hand, I select Bible, Trojan War from Greek mythology, Treasure Island by Robert Stevenson and The Swordsman by Jin Yong among which rudimentary knowledge about plant is analyzed in particular contexts.

Inductive method is utilized to sum up what was mentioned above, integrate a same plant's differences and similarities in different culture and contexts and come up with some suggestions that when reading stories or novels, one takes more notice of plant which may trigger possible change or propulsion of plots.

\section{Seven Types of Meaning by G. Leech}

The word "meaning" itself has different meanings. This is a big difficultly in the study of meaning. In the book The Meaning of Meaning in 1923, C. K. Ogden and I. A. Richards presented a "representative list of the main definitions which reputable students of meaning have favored". There are 16 major categories of them, with sub-categories all together, numbering 22.

Leech recognizes seven types of meaning in his Semantics, first published in 1947, four types as follows:

Conceptual Meaning is concerned with the relationship between a word and the thing it denotes, or refers to. In this sense, conceptual meaning overlaps, to a large extent, with the notion of REFERNCE. But Leech also uses "sense" as a verifier term for his conceptual meaning. As a result, Leech's conceptual meaning has two sides: sense and reference.

Connotative meaning means what is communicated by virtue of what language refers to.

Affective meaning is what is communicated of the feelings and attitudes of the speaker/writer. It mainly can be divided into commentary meaning, derogatory meaning and neutral meaning. The difference between politician and statesman, for instance, is that the former is derogatory and the latter is commendatory.

Reflective meaning refers to what is communicated through association with another sense of the same expression.

\section{Peter Newmark and His Translation Theory}

Peter Newmark (1916-2011), was an English professor of translation at the University of Surrey, who was associated with the founding and development of the Centre for Translation Studies at Surrey. Newmark was also one of the main figures in the founding of translation studies in the English-speaking world from the 1980s authoring A Textbook of Translation, Paragraphs on Translation, etc.

Peter Newmark, generally, introduces two kinds of translation methods and three kinds of text types (expressive text, informative text and vocative text). The methods are semantic translation and communicative translation. In fact, Peter Newmark thinks that all translations must be, to some degree, both communicative and semantic for it is merely a matter of emphasis. Communicative translation, however, is concerned mainly with the readers, usually in the context of a language and cultural variety which gives full consideration to reader's comprehension, while semantic translation is concerned with the author usually as an individual, and often in contradiction both to his culture and to the norms of his language for the purpose of the transmission of original literal information. He states clearly there is no purely semantic translation or purely communicative translation in translation practice, and only through a combination of the two methods can a translation be both accurate in meaning and acceptable to the target language reader.

A knowledge of translation method of the two kinds facilitates tremendously grasping the connotative meaning of plant and its author's attitude toward protagonist, the twists and turns of plots at the appearance of specific plant with special connotation, or not. 


\section{Eugene. A. Nida and His Dynamic Equivalence}

Nida (1914-2011), Christian since a young age, functions as the developer of the dynamic-equivalence Bible-translation theory. Nida was instrumental in engineering joint efforts between the Vatican and the United Bible Society (UBS) to produce cross-denominational Bibles in translations across the globe which was carried on in accordance with Nida's translation principle of Functional Equivalence, his most notable contribution to translation theory which is also known as Dynamic Equivalence throughout the world.

Nida distinguished two types of equivalence: Formal Equivalence and Dynamic Equivalence. By Formal Equivalence, he "focuses attention on the message itself, in both form and content" with aims to allow readers to understand as much SL context as possible. Dynamic Equivalence emphasizes more on the effect the readers receive the message with the aim to "relate the reader to modes of behavior relevant within the context of reader's own culture". Later, realizing that there is no absolute symmetry between languages, he preferred the term "functional equivalence" in the sense that "equivalence can be understood in terms of proximity", i.e. on the basis of degrees of closeness to functional identity.

In fact, Nida's Functional Equivalence is more or less the same with Communicative Translation. The difference is that Nida's theory can be used in all kinds of texts while Newmark's has divided the text into several categories.

\section{Problems Solving}

\section{Cultural Aspect of Plant in Treasure Island}

In Treasure Island, pines, willows, bulrush and swampy trees point out that the insular was desolated, sparsely populated but ecologically rich. I do not intend to follow in close detail all the plants appearing in Treasure Island, rather than describe a handful of plant smacking of saliently cultural connotation.

The most apparent turning point in this novel lies in, undoubtedly, that night on which Jim intercepted, by accident, what Silver intrigued with his accomplices, when he merely wanted to get an apple as snack, only to be welcome by an empty apple barrel where sheltered him in success.

Due to Jim's eavesdropping, this piece of news shocked everybody, including the Doctor. Then they began to play their cards in the circumstances of heads in number to beat Silver's gangs and to obtain the gold without a scratch. Compared with the prior spot line, the total narration reached the authentic high from "the apple event”.

In accordance with Eugene Nida's Functional Equivalence, only readership has a certain understanding of Greek Legend and the Bible, can they attach appropriate emphasis on these subtle details which may furtively imply some change about the spot once readership comes across clue of this kind.

In chapter XIII, "tall trees of the pine family" merely symbolizes that nearly no one ever stood on this desolated island and that in the weird-shaped land something scary and misery would come into being as their landing.

Pines, and bulrushes in the fiction possess no particular meanings, they are just ordinary plant. However, willows in western countries imply the sorrow of beloved's death which means that there will some people passing away, some around Jim the hero. Fratricide takes place in this island attributed to the greed for money. Pines in the chapter XXXII, "Sheer above us rose the Spyglass, here dotted with single pines, there black with precipices.” For my part, it may hold that greed ends miserable and that justice would prevail in the long run. 


\section{Cultural Aspect of Plant in The Swordsman}

In The Swordsman, the poplar wig appearing in Chapter 5 in description of Yi Lin, a Buddhist nun, to illustrate her sincere pray for Linghu Chong’s recovery. With this simile, sanctified Yi Lin turns into an angel with a sacred halo over her head, easing his trauma and relieving his misery. The goddess of mercy bottle, with poplar and willow wigs in it, is in the view world sound Avalokiteshvara hands treasured vase which helps the distressed infinitely merciful, it can spread blessing to the world, universals restoration. Thereupon, the poplar wig used to describe Yi Lin, the Buddhist nun, associates her figure with the divine Goddess Avalokiteshvara.

Many a chapter adopts pine trees, cypress and banyan trees in the emergence of Linhu Chong, especially it's the time to highlight his lofty personalities-tough and tensile, unyielding and gallant. For instance, Chapter 7, a notorious villain intends to murder Linghu Chong by taking advantage of Linghu's precarious situation, at that emergency, Linghu, backed by a pine trunk, retrieved strength and courage for its rescue.

Meanwhile, bamboo in this novel plays its cards right in the manifestation of Linghu's virtuousness and nobleness, in strong contrast to those who are authentically dirty dogs in the disguise of heroic figures. Those hypocrites to the beginning are to the river and lake like a duck to the water, only to have their life terminated miserably, attaining their due, such as Yue Buqun and Lin Pingzhi.

Another kind of salient and culturally relevant plant in this novel lies in Chapter 36 where Linghu Chong and Ren Yingying sheltered in a virgin valley teeming with birds chirping, flowers blooming and brooks murmuring, a valley engirdled by dense woods. There also stand a mass of peach trees bearing peaches, the overripen falling down on the meadow diffusing tempting sweet fragrance. One early morning, Ling intends to pick peaches for Yingying, for breakfast. At the sight of so many peaches, on the trees and meadow, he recalls Tao Gu Liu Xian, a nickname of six humor-natured brothers, considers in mind that once winding up turbulence, he, with Yingying, would like to seclude in this remote and peaceful valley for good and bearing some babies as lovely as Tao Gu Liu Xian in this heavenly Shangri-La. At that moment, something beautiful rises in his heart.

\section{Function of Plant in Treasure Island}

From the above analysis, the core turning point of the spot line undoubtedly goes to the night when Jim wanted an apple, only to find the apple barrel empty, intercepting by accident Silver's trick of looting all the treasure. In reference to the Greek Legend and the Bible, the apple of Discord and the apple eaten by Adam and Eve imply that this apple put at this crucial turning point is not an accident, it reminds readership of some changes on the way, of the story not continuing plainly and smoothly as expected.

The whole story reaches climax from that special late night, and the thought of an apple arising in Jim symbolizes his eavesdropping Silver's intrigue without which the journey would be colorless and ripples, no twists or turns, or even be sifted out in the river of history.

Other kinds of plant, weird-shaped and old-aged, in Treasure Island in part apply colors to the uncanny and ghastly surroundings, add intension to the road of evacuation for treasure; in part hint an image of virgin forest with no deforestation which is found in both Treasure Island and the Swordsman.

\section{Function of Plant in The Swordsman}

More kinds of plant and more cultural meanings in this novel than those in Treasure Island, here I prefer to a couple of culturally prominent plants.

As the detailed elaboration in prior chapters, it's known that pines, cypresses and banyans, as well as 
bamboos, all of these indicate, to a full degree, Linghu Chong's noble and virtuous characteristics. Sometimes, shows his unyieldingness; sometimes his toughness and tolerance and sometimes his courage.

The poplar wig for sanctifying Yi Lin functions as heart-felt praying of Linghu Chong, in manifestation to her pious and loyal to Lord Buddha. By doing so, Yi Lin seems to be surrounded by divine light like a nymph with good nature. She is pure, and so is her love of Linghu Chong.

The peaches in valley, a real Shangri-La carries Linghu Chong's aspiration for secluding from rivers and lakes and living, with Ren Yingying, a peaceful, unbothered life forever. In ancient Chinese script, The Tale of Shangri-La (Tao Hua Yuan Ji), an imaginary Utopia, narrates an ideal secluded place where people live a life with no war, no class system or no crime, like a communistic miniature. In the turmoil of the era, ordinary people, peasants in particular, merely long to put something on dining-table, to sleep a sleep without nightmare and to put every member of the family together. All Linghu Chong dreams of is just to spend every moment with Ren Yingying, peacefully and felicitously.

\section{Correlation}

No matter what difference exists between Peter Newmark's semantic or communicative translation theory and Eugene Nida's Functional Equivalence, their common and final objective is to enable readership to grasp what one specific article intends to disseminate to the world. The Chinese culture does not totally and perfectly correspond to the Western culture in terms of plant's connotation, thus the gap between them requires readers' attention to plant's cultural background.

Pines, swallows and so on appearing in both novels play distinct roles in respective context, due to different cultural background and particular intention of the two authors. What is more, the apple merely takes shape in Treasure Island, but The Swordsman, thus comparison finds no way at this time. By the same token, the peach in The Swordsman does not turn up in Treasure Island.

\section{Conclusion}

Leech's seven types of meaning suggest that there are different layers of meaning, it is connotation that is the authentic intention and meaning of the speaker. Semantic and communicative translation theory by Peter Newmark illustrates that translation method should be adopted in specific context in order to better express what the context really wants to say. Nida's Functional Equivalence holds that when translating, translators ought to consider from readers' angle, attempting to express with the most appropriate words in pursuit of spreading underlying meaning of the original context.

Treasure Island and The Swordsman share something in common, both in spot line and genre. Unfortunately, with the limit of writing skills, the depth and profoundness of thought and the level of professional knowledge, it's beyond me to handle the field. My part here is merely to draw academia's attention to this topic, to slightly analyze the two books through what I comprehend about them.

In order to comprehend the two novels and to learn profoundly translation theories, such as Newmark's and Nida's theories, it's told to read extensively western folklores, legends and fairy tales as well as the Bible. Meanwhile, traditional Chinese ones should not be neglected either. What is more, when savoring literature, one may as well place great emphasis on something that generally is associated with cultural background. A third suggestion is that one develops a habit of connecting plant to its underlying story and connotation through regular practice. Once the relevance established, it becomes much easier to understand author's hidden thought 
and to grasp the outline, thereupon shape of the spot line is taken clearly and vividly before one's eyes.

As detective novels require scrupulousness and meticulousness altogether with sensitivity of relevance, Sometimes, though not always, subtle clues or humble detail emerging in a novel may be a key to the development of the whole story. With the development of translation theories and the help of academic globalization, the cultural connotation of plant and its textual function will be further probed. Moreover, this topic shall flourish in full swings.

\section{References}

Bao, H. (2001). Cultural Connotation and Language Translation. Beijing: China Translation and Publishing Corporation. Chen, M. (2001). On the Artistry of Jin Yong's Fiction. Nanchang: Baihuazhou Literature \& Art Press.

Deng, Y. (1997). Language and culture. Beijing: Foreign Language Teaching and Research Press.

Du, J. (2009). Imploration of “Flowers” Annotation. People’s Music, No. 57.

Fromkin, V. etc. (2008). An Introduction to Language. Beijing: Peking University Press.

Jia, Y. (1997). Crosscultural Communication. Shanghai: Shanghai Foreign Language Education Press.

McCarthy, D. (1997). English Idioms and Sayings. Beijing: China Translation and Publishing Corporation.

Nida, E. A. (1993). Language, Culture and Translation. Shanghai: Shanghai Foreign Language Education Press.

Ni, K. (1997). My View on Jin Yong Novels. Taipei: Taipei Yuan-Liou Publishing Co., Ltd.

Peter Newmark. (2001). A Textbook of Translation. Shanghai: SH Foreign Language Education Press.

Zhang, A., \& Yang, Y. (2002) Contrast Analysis of English and Chinese Plant Words' Cultural Associative Meaning. Language Teaching and Linguistic Studies, 4, 74-80.

Zhao, Dan. (2009). On Artistic Writing Characteristics of Jin Yong's Novels Artistic. Journal of Nanchang University, 1, 39-42.

Zhao, G. (1990). Reproduction Worship Multiculturalism. Beijing: China Social Sciences Press. 